\title{
VIDEO PROMOSI JURUSAN SISTEM INFORMASI BERBASIS MOTION GRAPHIC PADA STMIK RAHARJA TANGERANG
}

\author{
Lusyani Sunarya ${ }^{1}$ \\ Nesya Elvina Ayudita ${ }^{2}$ \\ Satria Agung Prabawa ${ }^{3}$ \\ Dosen STMIK Raharja ${ }^{1}$, STMIK Raharja Jurusan Manajemen Informatika ${ }^{2}$, \\ STMIK Raharja Jurusan Teknik Informatika ${ }^{3}$ \\ Jl. Jenderal Sudirman No.40 Modern Cikokol - Tangerang \\ E-mail: lusyani@raharja.info ${ }^{1}$, nesya@raharja.info ${ }^{2}$, satria.agung@raharja.info ${ }^{3}$
}

\begin{abstract}
ABSTRAK
Pada era globalisasi saat ini, persaingan dalam dunia pendidikan semakin ketat, oleh karena itu dibutuhkan strategi yang tepat dalam mencapai keberhasilan.Tujuan penelitian ini adalah untuk membantu Jurusan Sistem Informasi STMIK Raharja dalam upaya meningkatkan kepeminatan calon mahasiswa/i baru untuk bergabung di Jurusan SI STMIK Raharja. Permasalahan yang terdapat di jurusan Sistem Informasi STMIK Raharja sebelumnya adalah, Jurusan Sistem Informasi dalam kegiatan promosinya hanya menggunakan media cetak, belum ada media dalam bentuk video promosi yang menjelaskan secara lengkap mengenai informasi jurusan SI yang dikemas secara menarik. Metode penelitian yang digunakan yaitu : analisa permasalahan, pengumpulan data, analisa perancangan media dan konsep produksi media (KPM). Hasil penelitian ini yaitu video promosi berbasis motion graphic $2 D$ yang mencakup unsur gerak, gambar, suara, dan juga musik yang menjelaskan secara detail mengenai profil jurusan Sistem Informasi STMIK Raharja, konsentasi yang ada di Jurusan Sistem Informasi, fasilitas, keunggulan, dan metode pembelajaran. Implementasi dari video promosi ini akan ditunjukan kepada calon mahasiswa/i baru yang berminat untuk mengambil jurusan Sistem Informasi dan sebagai media informasi dan promosi bagi masyarakat luas. Melalui perancangan media video promosi jurusan SI STMIK Raharja ini akan meningkatkan kepeminatan calon mahasiswa/i baru pada jurusan SI STMIK Raharja setiap tahunnya dan sebagai sarana informasi yang bermanfaat bagi masyarakat.
\end{abstract}

Kata kunci-Video, Promosi, Jurusan Sistem Informasi

\begin{abstract}
ABTRACT
In the current era of globalization, competition in education increasingly tight, therefore it takes the right strategy in achieving success. The purpose of this study is to assist the Department of Information Systems STMIK Raharja in an effort to improve the new student candidates to join the Department of SI STMIK Raharja. Problems that exist in the department of Information Systems STMIK Raharja previously is, Department of Information Systems in promotional activities only use print media, there has been no media in the form of a promotional video that explains in full about information majors Information Systems are packaged attractively. The research method used are: problem analysis, data collection, media design analysis and media production concept.The result of this research is motion graphic $2 D$ promotional video which includes motion, picture, sound, and music element which explains in detail about department profile STMIK Raharja Information System, the existing concentration in Department of Information System, facilities, excellence, and learning method. Implementation of this promotional video will be shown to prospective new students who are interested to major in Information Systems and as a medium of information and promotion for the wider community.Through the design of video promotion media Department of Information Systems STMIK Raharja this will enhance the new prospective student candidate in the department of Information Systems STMIK Raharja every year and as a means of useful information for the communit.
\end{abstract}

Keywords - Video, Promotion, Department of Information System. 


\section{PENDAHULUAN}

Pada era globalisasi saat ini, persaingan dalam dunia pendidikan semakin ketat, oleh karena itu dibutuhkan strategi promosi yang tepat untuk mencapai keberhasilan dalam memasarkan suatu Jurusan, agar diminati oleh banyak orang.

Dalam memasarkan sebuah Jurusan di Perguruan Tinggi, membutuhkan media video promosi berupa media audio visual dengan durasi yang singkat namun dapat mempromosikan secara detail sehingga menjadi lebih menarik bagi konsumen ${ }^{[1]}$.

Sehingga dapat menjadi sarana efektif dalam menunjang kegiatan promosi dan informasi jurusan.Promosi adalah tindakan menginformasikan atau meningkatkan konsumen tentang spesifikasi produk atau merek ${ }^{[2]}$.Dari sarana media yang digunakan setiap periode yang telah ditentukan, tentunya telah dilakukan evaluasi secara seksama agar program promosi waktu mendatang mempunyai nilai peningkatan efektifitas yang lebih baik dibandingkan waktu sebelumnya.

Jurusan Sistem Informasi jenjang Strata Satu pada STMIK Raharja merupakan salah satu program studi dibidang ilmu teknologi komputer yang memiliki 3 Konsentrasi yaitu Business Intelligence(BI), Management Information System, dan Computer Accountancy.Konsentrasi Unggulan di dalam jurusan Sistem Informasi ini adalah Business Intelligence.Tujuan penelitian ini adalah untuk membantu jurusan Sistem Informasi STMIK Raharja dalam upaya meningkatkan kepeminatan calon mahasiswa/i baru untuk bergabung di Jurusan SI STMIK Raharja.

Permasalahan yang terdapat di Jurusan Sistem Informasi STMIK Raharja sebelumnya adalah, Jurusan SI dalam kegiatan promosinya hanya menggunakan media cetak, belum ada media dalam bentuk video promosi yang menjelaskan secara lengkap mengenai informasi jurusan SI yang dikemas secara menarik. Perancangan video promosi ini dibutuhkan oleh bagian pemasaran dalam upaya promosi jurusan SI STMIK Raharja untuk menarik minat calon mahasiswa/i baru untuk bergabung di jurusan SI, selain itu pada jurusan Sistem Informasi STMIK Raharja belum ada media yang efektif dalam menyampaikan informasi jurusan SI yang menjelaskan secara detail mengenai profil jurusan SI STMIK Raharja, konsentasi yang ada di Jurusan SI STMIK Raharja, fasilitas, keunggulan, dan metode pembelajaran.

Hasil penelitian ini yaitu berupa perancangan video promosiberbasis motion graphic 2 Dadalah grafis yang menggunakan video dan animasi untuk menciptakan ilusi dari gerak ataupun transformasi ${ }^{[3]}$, yang mencakup gambar, suara, dan juga musik yang menjelaskan secara detail mengenai profil jurusan SI STMIK Raharja, konsentasi yang ada di jurusan SI, fasilitas, keunggulan, dan metode pembelajaran. Implementasi dari video promosi ini akan ditunjukan kepada calon mahasiswa/i baru yang berminat untuk mengambil jurusan Sistem Informasi dan sebagai media informasi dan promosi bagi masyarakat luas. Strategi promosi yang dilakukan yaitu : video promosi jurusan SI ini akan di tayangkan pada saat kegiatan GCC Tour, Presentasi internal oleh bagian marketing, Presentasi ke sekolah-sekolah SMA/SMK, education fair, dan berbagai kegiatan promosi lainnya dalam upaya meningkatkan angka pendaftaran mahasiswa/i baru jurusan SI STMIK Raharja setiap tahunnya.

Melalui perancangan media video promosi jurusan SI STMIK Raharja ini akan meningkatkan kepeminatan calon mahasiswa/i baru pada jurusan SI STMIK Raharja setiap tahunnya dan sebagai sarana informasi yang bermanfaat bagi masyarakat.

\section{LITERATURE REVIEW}

1. Penelitian yang dilakukan Win dan Aileena Solicitor Costa Rica El Chidtian $(2015)^{[4]}$ dengan judul "Video Motion Graphic Sebagai Promosi Perpustakaan Bank Indonesia". Penelitian ini menjelaskan Video promosi yang menggunakan konsep perpaduan antara motion dan juga video liveshoot, penggunaan motion graphic dan juga motion trackingyang berguna sebagai media baru dalam menginformasikan sebuah perpustakaan sehingga menarikdalam memberikan informasi kepada masyarakat mengenai sejarah bangunan dan pendiriannya.

2. Penelitian yang dilakukan Abdillah, dkk $(2014)^{[5]}$ dengan judul "Perancangan Video Profile sebagai Media Promosi STMIK CIC dengan Tehnik Motion Graphic menggunakan Perangkat Lunak Komputer Graphic".media promosi berbentukvideo profile dengan teknik 
Motion Graphic dengan objek Flat Design. Teknik ini sangat menarik dan inovatif sehingga mempunyai daya tarik tersendiri bagi yang melihatnya, video profil ini akan digunakan saat kunjungan sosialisasi kampus ke sekolah-sekolah serta dibagikan melalui media sosial. Adobe After Effects, Adobe Media Encoder dan CorelDraw adalah Software yang digunakanuntuk membuat teknik Motion Graphic dan Nuendo untuk perekam narasi.

3. Penelitian yang dilakukan Anita, dan Fitri Marisa (2017) ${ }^{[6]}$ dengan judul "Rancangan Video Media Promosi Berbasis Motion Graphic 2DUntuk Meningkatkan Jumlah Mahasiswa Universitas Widyagama Malang" penelitian tersebut menjelaskan tentang perancangan media promosi Universitas Widyagama Malang dengan konsep animasi 2D. Hal ini dikarenakan sebuah informasi akan lebih mudah diserap dengan penyajian informasi melalui audio dan melalui visual. Animasi yang dirancang dalam bentuk 2D yang menjelaskan dan memperkenalkan universitas widyagama malang. Animasi 2D ini dibuat dengan menggunakan Macromedia Flash 8. Diedit dengan Adobe Premiere.

4. Penelitian yang dilakukan Yeresella, dkk $(2016)^{[7]}$ dengan judul penelitian "Perancangan Video Sosialisasi Bahaya Rokok bagi Ibu Hamil dan Janin Berbasis Motion Graphic" penelitian tersebut menjelaskan tentang perancangan video sosialisasi bahaya rokok bagi ibu hamil dan janin dalam bentuk video motiongraphic. Hasil dari perancangan ini yaitu video sosialisasi tentang bahan-bahan berbahaya pada rokok, bahaya apa saja yang akan dialami, dan mengatasinya.

5. Penelitian yang dilakukan Brigitta, dkk $(2016)^{[8]}$ dengan judul penelitian "Perancangan Video Company Profile Lembah Kamuning Dairy Farm, Desa Cigugur, Kuningan dengan Teknik Motion Graphic" penelitian tersebut menjelaskan tentang informasi public tentang lembah kamuning dairy farm. Motion graphic cocok untuk profil perusahaan ini karna informasinya mudah diingat dan lebih menarik.

\section{METODE PENELITIAN}

Metode penelitian yang dilakukan, dalam merancang Video Promosi pada Jurusan Sistem Informasi STMIK Raharja adalah sebagai berikut : (1) Analisa Permasalahan didapatkan dari hasil interview yang dilakukan pada bagian marketing STMIK Raharja. (2) Pengumpulan Data yang dilakukan dengan cara Observasi, Interview, dan Studi Pustaka. (3) Analisa Perancangan Media video promosi yang dibutuhkan oleh Jurusan Sistem Informasi STMIK Raharja, akan diproduksi dengan menggunakan aplikasi program komputer grafis diantaranya : After Effects Cs6, Adobe Illustrator Cs6, dan Adobe Audition Cs6 danMetode Konsep Produksi Media (KPM) : Perancangan media video promosi melalui beberapa tahapan perancangan agar mendapatkan suatu gambaran tentang produk yang akan dibuat. Sehingga memudahkan kita dalam pembuatan video promosi. Tahapan yang dilakukan yaitu sebagai berikut :

1. Preproduction

2. Production

3. Postproduction

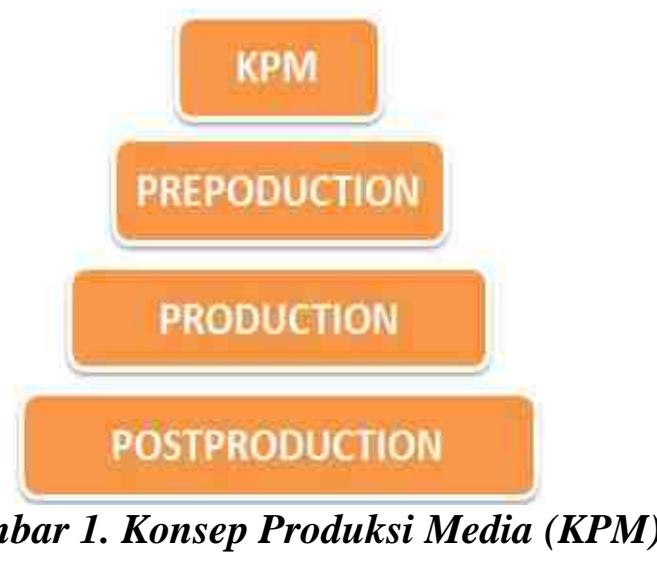

Gambar 1. Konsep Produksi Media (KPM) 
HASIL DAN PEMBAHASAN

Preproduction

Preproduction adalahlangkah awal suatu karya yang akan kita mulai diantaranya ide, perencanaan, danpersiapan dari Konsep Produksi Media. Terdapat tujuh langkah Preproduction dalam Konsep Produksi Media, dimulai dari Ide yang dituangkan secara sistematis, lalu kemudian pembuatan sinopsis, scriptwritting, dan storyboard.pemilihan pemain (crew\& talent)Dua tahapan terakhir adalah setting alat dan time schedule.

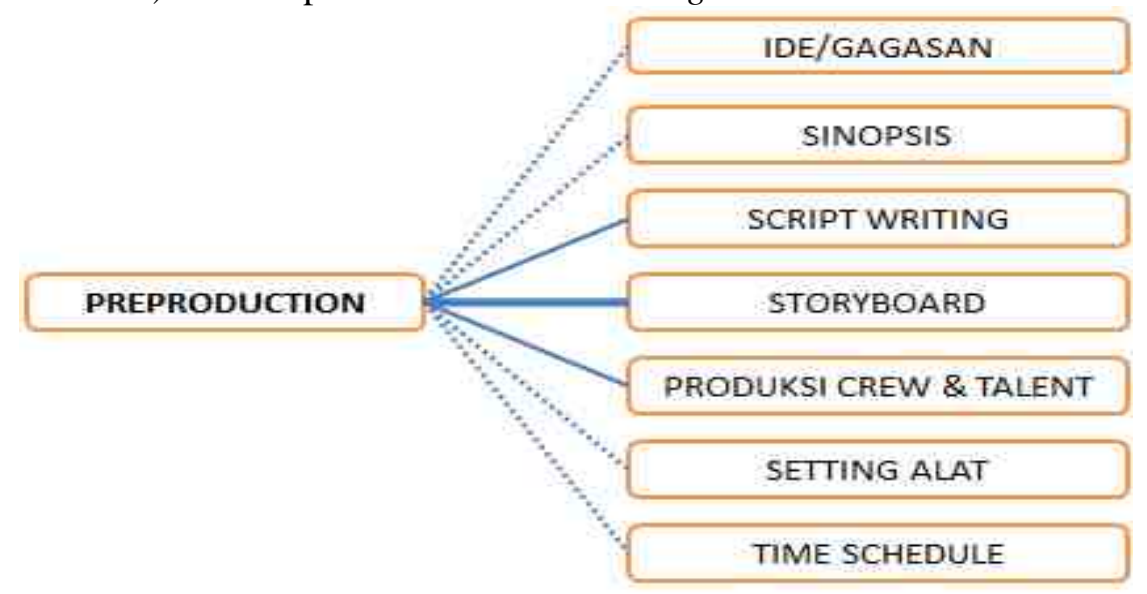

\section{Ide/Gagasan}

\section{Gambar 2. Preproduction}

Media informasi merupakan realisasi dari sebuah ide pemikiran yang telah kita masukkan kedalam video. Pembuatan media informasi dan promosi ini mengambil ide dari profile Jurusan Sistem Informasi STMIK Raharja. Multimedia berupa video promosi yang menampilkan profil jurusan Sistem Informasi STMIK Raharja, konsentasi yang ada di Jurusan Sistem Informasi, fasilitas, keunggulan, dan metode pembelajaran di jurusan Sistem Informasi STMIK Raharja.Media promosi dan informasi berupa video promosiyang dibuat mengambil garis besar dari ide tersebut.

\section{Sinopsis}

Sinopsis adalah ringkasan cerita dari sebuah media periklanan atau film, menjadi bentuk pemendekan dari sebuah featuredocumenter dengan tetap memperhatikan unsur yang ada pada feature documenter tersebut.

Tujuan membuat sinopsis adalah untuk menjelaskan secara singkat mengenai alur cerita video promosi jurusan Sistem Informasi STMIK Raharja yang dibuat.Adapun sinopsis dari video promosiini adalah:

"Sistem Informasi adalah salah satu program studi di bidang ilmu teknologi komputer pada STMIK Raharja yang berada di wilayah Kota Tangerang, yang bertujuan untuk menciptakan sumber daya manusia siap terap yang mampu menguasai, menerapkan, serta mengembangkan informasi yang meliputi :konsentrasi Business Intelligence (BI), Management Information System, dan Computer Accountancy.Fasilitas yang terdapat di Jurusan SI STMIK Raharjaadalah meliputi :Ruang Kelas, Lab Ilearning, Lab Komputer, REC (Raharja Enrichment Center), Perpustakaan, Aula, Green Max Theater(GMT). Jurusan SI STMIK Raharjasudah terakreditasi Bdan berstandar ISO 9001:2008. Metode pembelajaran untuk konsentrasi unggulan yaituBusiness Intelligence (BI) menggunakan metode iLearning dengan iPad sebagai media pembelajarannya, sedangkan untuk Management Information System, dan Computer Accountancymerupakan kelas regular non iLearning”.

\section{Script Writing}

Membuat rancangan penulisan naskah secara rinci yang mengembangkan ide atau gagasan yang sudah kita buat pada sinopsis menjadi sebuah konsep yang menarik.Script Writing dalam video promosi ini adalah :

\section{Tabel 1.Script Writing}


ISSN: 2461-1409

\begin{tabular}{|c|c|c|}
\hline NO. & TAKE SCRIPT & KETERANGAN \\
\hline 1 & Take Script 1 & $\begin{array}{c}\text { Bumper Opening, } \\
\text { Menampilkan Gambar Gedung STMIK Raharja Tangerang }\end{array}$ \\
\hline 2 & Take Script 2 & Menampilkan Ketua STMIK Raharja \\
\hline 3 & Take Script 3 & $\begin{array}{c}\text { Menampilkan penjelasan profil Jurusan SI STMIK Raharja } \\
\text { oleh Kaprodi SI STMIK Raharja }\end{array}$ \\
\hline 4 & Take Script 4 & $\begin{array}{c}\text { Menampilkan Penjelasan Program Studi SI dan } \\
\text { Visi, Misi Jurusan SI STMIK Raharja }\end{array}$ \\
\hline 5 & Take Script 5 & Menampilkan fasilitas Jurusan SI STMIK Raharja \\
\hline 6 & Take Script 6 & $\begin{array}{c}\text { Menampilkan metode pembelajaran jurusan SI STMIK } \\
\text { Raharja }\end{array}$ \\
\hline 7 & Take Script 7 & Menampilkan metode pembelajaran di dalam kelas \\
\hline 8 & Take Script 8 & Promosi Jurusan SI \\
\hline 9 & Take Script 9 & Bumper Ending \\
\hline
\end{tabular}

\section{Storyboard}

Storyboard berisi rancangan atau rangkaian jalannya cerita yang berupa sketsa gambar yang dilengkapi dengan petunjuk atau catatan pengambilan gambar, yang nantinya akan dipergunakan untuk kebutuhan sebelum melakukan shooting, sehingga kita mempunyai gambaran pada saat proses production. Selama proses preproduction, perencanaan yang berhubungan dengan visualiasasi yang akan dibuat membutuhkan media storyboard.

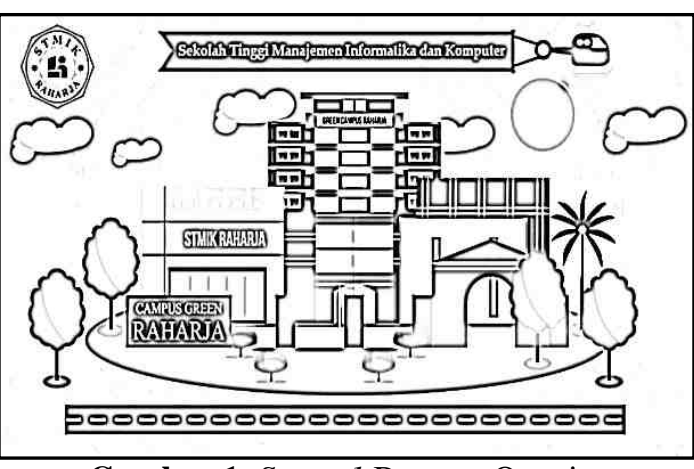

Gambar 1. Scene 1.Bumper Opening Menampilkan gedung STMIK Raharja

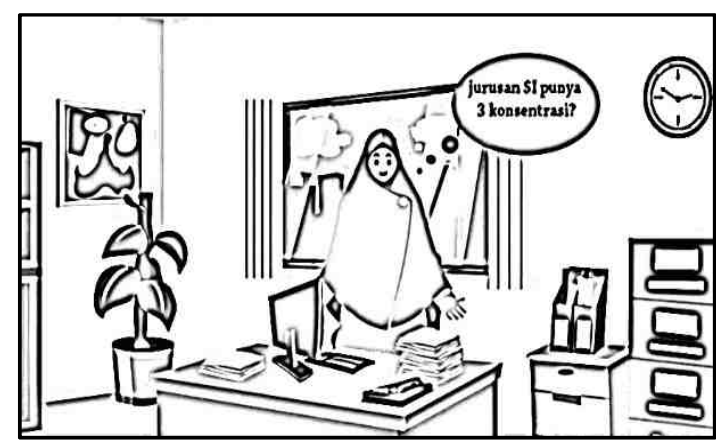

Gambar 3. Scene 3.Menggambarkan penjelasan Kaprodi tentang program studi Sistem Informasi.

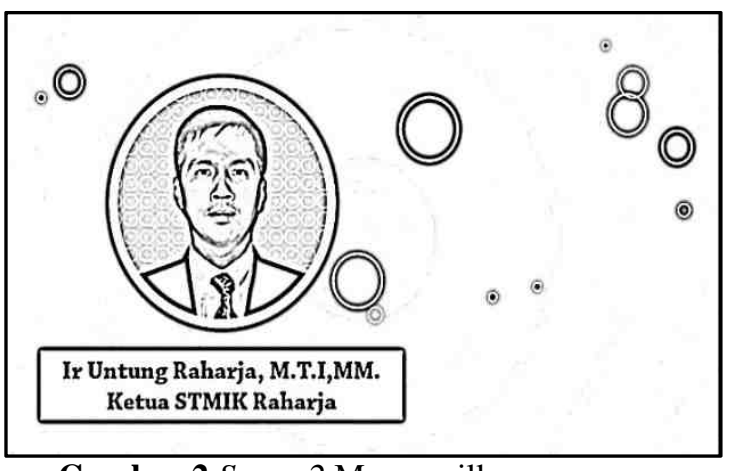

Gambar 2 Scene 2.Menampilkan Ketua STMIK Raharja

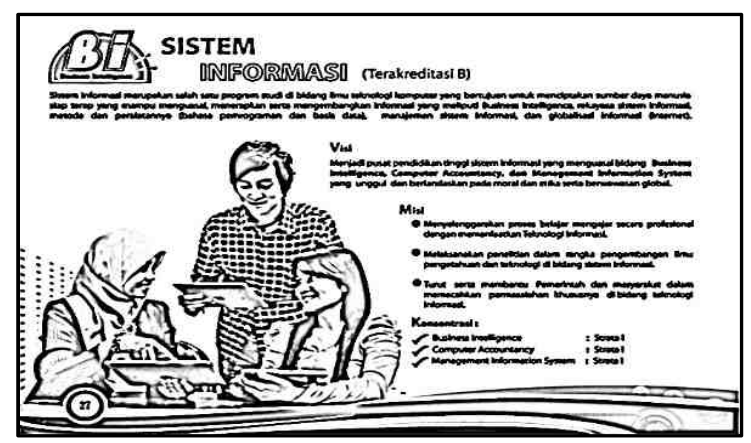

Gambar 4. Scene 4. Profil Jurusan dan Visi Misi Program studi Sistem Informasi. 


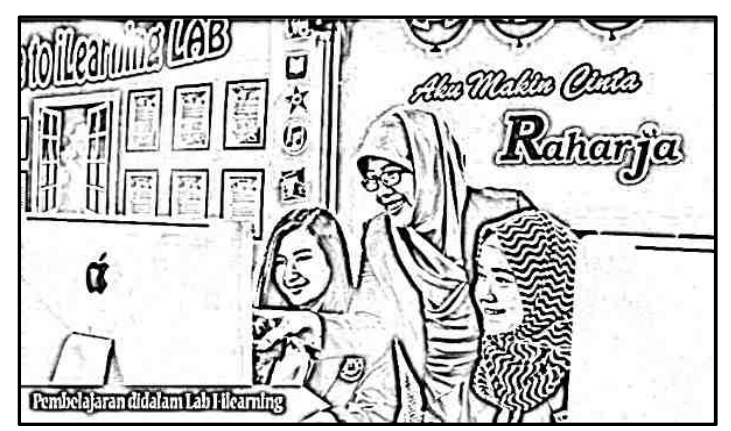

Gambar 5.Scene 5.Fasilitas jurusan Sistem Informasi.

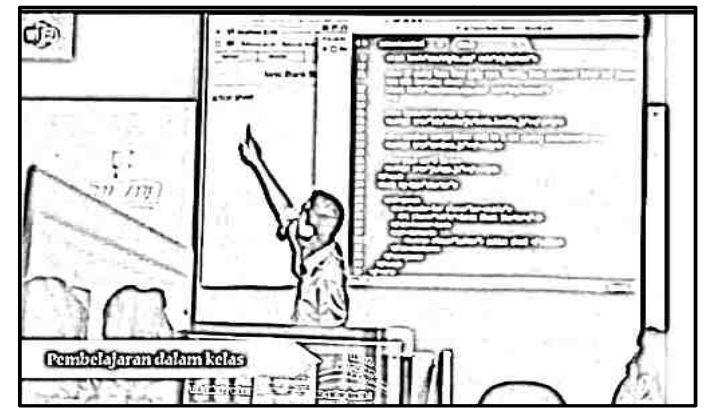

Gambar 7.Scene 7.Menampilkan Metode Pembelajaran dalam kelas

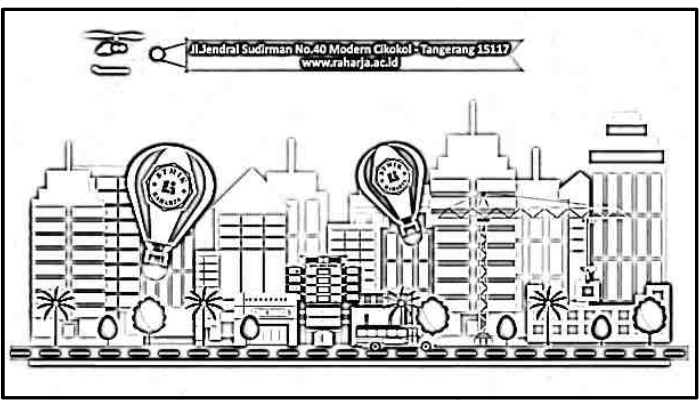

Gambar 9. Scene 9. Bumper Ending

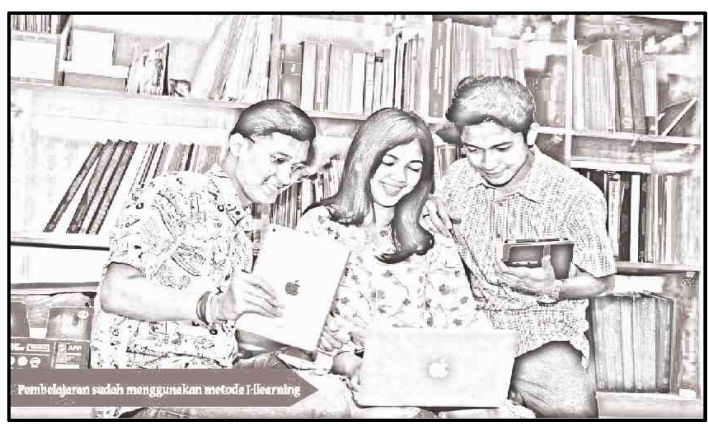

Gambar 6. Scene 6. Metode pembelajaran Jurusan Sistem Informasi.

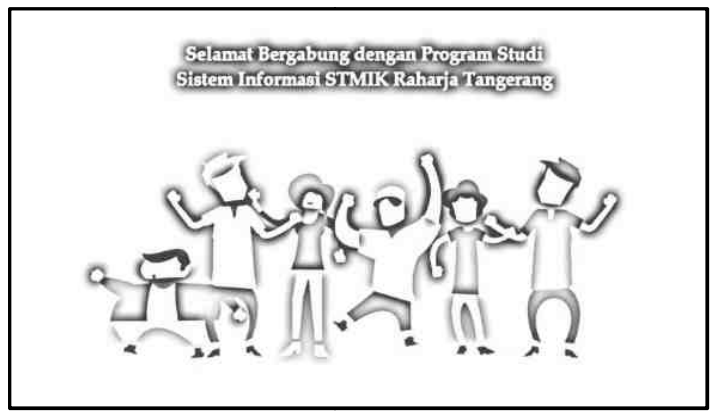

Gambar 8. Scene 8.Promosi Jurusan Sistem Informasi STMIK Raharja

\section{Produksi Crew \& Talent}

Crew \& Talentsecara garis besar dibutuhkan Sutradara, Asisten Sutradara, Cameramen, Editor, Script Writting, Dubber dan Pemain atau pemeran dari video promosi jurusan Sistem Informasi ini adalah Ketua STMIK Raharja, Kaprodi SI STMIK Raharja, Mahasiswa/i STMIK Raharja, dan Dosen STMIK Raharja.Berikutpemain dan crew yang terlibat dalam pembuatan video promosi jurusan Sistem Informasi STMIK Raharja ini, antara lain:

Tabel 2.Crew \& Talent

\begin{tabular}{|l|c|c|}
\hline NO. & JABATAN & NAMA \\
\hline 1 & Sutradara & Hadi Wibowo \\
\hline 2 & Asisten Sutradara & Lusyani Sunarya \\
\hline 3 & Cameraman 1 & Yuliadi Saputra \\
\hline 4 & Cameraman 2 & Fahmi Husnaini \\
\hline
\end{tabular}




\begin{tabular}{|l|c|c|}
\hline 5 & Editor & Satria Agung Prabawa \\
\hline 6 & Dubbing & Herry Roshan \\
\hline 7 & Script Writing & Nesya Elvina Ayudita \\
\hline 8 & & Ketua STMIK, Kaprodi \\
& PI, Dosen, dan \\
& & $\begin{array}{c}\text { Mahasiswa/i Jurusan SI } \\
\text { STMIK Raharja }\end{array}$ \\
\hline
\end{tabular}

\section{Setting Alat}

Dalam pembuatan video promosi jurusan Sistem Informasi ini, menggunakan alat-alatseperti Camera, Tripod, dan Microphone.Untuk Camera yang digunakan yaitu :Camera Cannon 60D. Dalam pembuatan Video promosi Jurusan Sistem Informasi ini banyak menggunakan lokasi indoor. Tripod menggunakan SLIK dengan kualitas standar dan juga perangkat tambahan menggunakan slideragar pergerakan gambar pada camera tampak lebih smooth dan bagus

\section{Time Schedule}

Tabel 3.Time Schedule

\begin{tabular}{|c|c|c|c|c|c|c|c|c|c|c|c|c|c|c|c|c|c|}
\hline \multirow{2}{*}{ Tahapan } & & \multicolumn{4}{|c|}{ Aug-17 } & \multicolumn{4}{|c|}{ Sep-17 } & \multicolumn{4}{|c|}{ Oct-17 } & \multicolumn{4}{|c|}{ Nov-17 } \\
\hline & & 1 & 2 & 3 & 4 & 1 & 2 & 3 & 4 & 1 & 2 & 3 & 4 & 1 & 2 & 3 & 4 \\
\hline \multirow{7}{*}{ 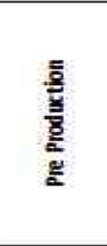 } & Ide & & & & & & & & & & & & & & & & \\
\hline & Time Schedule & & & & & & & & & & & & & & & & \\
\hline & Sinopsis & & & & & & & & & & & & & & & & \\
\hline & Script Writing & & & & & & & & & & & & & & & & \\
\hline & Storyboard & & & & & & & & & & & & & & & & \\
\hline & \begin{tabular}{|c|} 
Pemilihan \\
Pemain dan crew
\end{tabular} & & & & & & & & & & & & & & & & \\
\hline & Setting Alat & & & & & & & & & & & & & & & & \\
\hline \multirow{4}{*}{ 홀 } & $\begin{array}{l}\text { Perancanaan } \\
\text { Multimediáa }\end{array}$ & & & & & & & & & & & & & & & & \\
\hline & $\begin{array}{c}\text { Perancanaan } \\
\text { Audio }\end{array}$ & & & & & & & & & & & & & & & & \\
\hline & $\begin{array}{c}\text { Perancanaan } \\
\text { Visual }\end{array}$ & & & & & & & & & & & & & & & & \\
\hline & $\begin{array}{l}\text { Perancanaan } \\
\text { Broadcasting }\end{array}$ & & & & & & & & & & & & & & & & \\
\hline 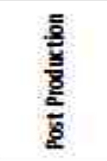 & $\begin{array}{l}\text { Capturing, } \\
\text { Editing, Mixing. } \\
\text { dan Finising }\end{array}$ & & & & & & & & & & & & & & & & \\
\hline
\end{tabular}

\section{Production}

Tahapan production adalah tahap berikutnya dalam konsep produksi media. Dalam proses produksi, dimana kerjasama antara talent dan crew sangat dibutuhkan. Karena dengan kerjasama yang baik antara talent dan crew, maka proses production pun berjalan lancar. Bahkan setiap crew dari masing - masing jobdesk harus menjalin kerjasama yang solid.Oleh karena itu pada tahap preproduction, semua yang bersangkutan mengenai production harus sudah dipersiapkan secara matang, misalnya job desk masing-masing crew dan talent harus jelas.Ada beberapa hal yang perlu diperhatikan dalam tahap Production video promosi ini diantaranya : perencanaan multimedia, perencanaan audio atau musik yang digunakan dalam video promosi ini, perencanaan visual meliputi visual atau gambar apa saja yang ditampilkan dalam video promosi ini, perencanaan broadcasting berkaitan dengan implementasi dan distribusi hasil dari video promosi jurusan SI ini. Dalam tahapan ini juga, peran dari sutradara sangat penting dibutuhkan dalam mengatur dan mengarahkan talent yang terlibat agar jalan cerita sesuai dengan sinopsis yang telah dibuat pada tahap preproduction. 


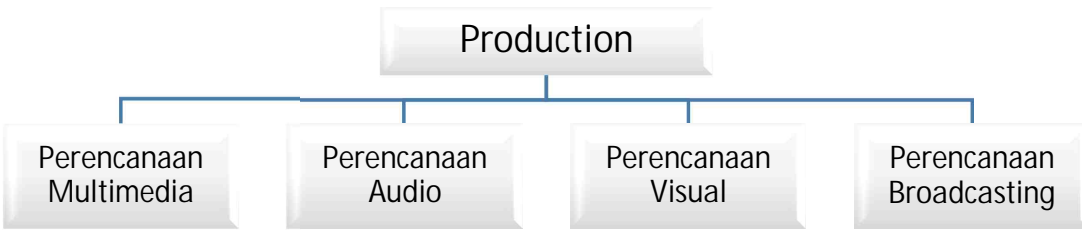

Gambar 10. Production

\section{Postproduction}

Postproduction adalah langkah selanjutnya yang merupakan langkah akhir atau finishing dari sebuah karya sampai menjadi sebuah video yang utuh.Sehingga mampu menyampaikan isi atau pesan yang terdapat dalam video kepada audience. Dalam proses postproduction pengolahan atau editing yang dilakukan meliputi aspek suara, gambar, dan alur cerita sesuai sinopsis video promosi yang di dapat dari proses production. Yang kemudian dikumpulkan di edit oleh seorang editor. Kegiatan pemutaran dan distribusi juga termasuk di dalam proses postproduction.

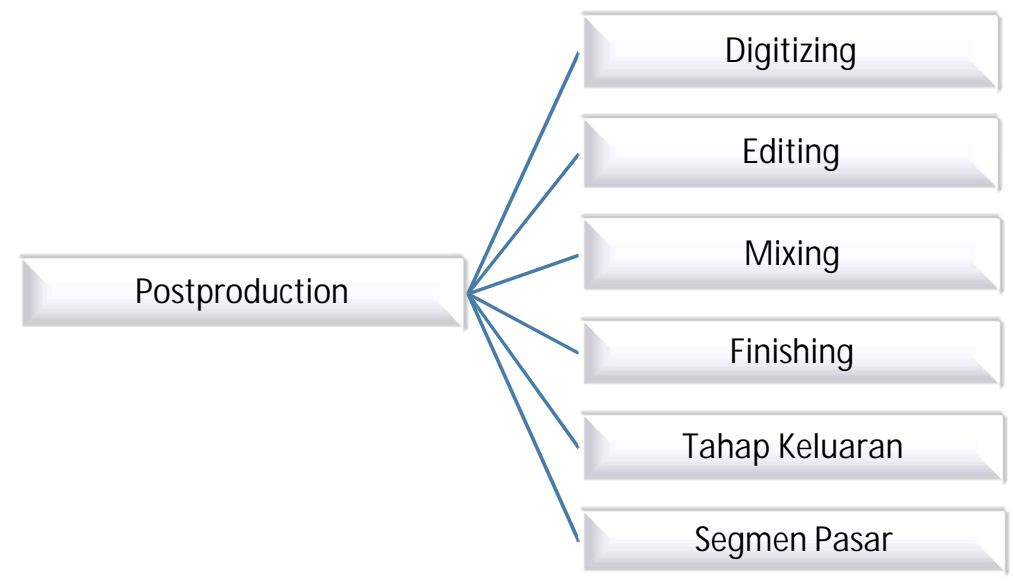

\section{Tampilan Isi}

\section{Gambar 11.Post Production}

Tampilan isi mengambil dari profil jurusan SI STMIK Raharja, konsentasi yang ada di Jurusan SI STMIK Raharja, fasilitas, keunggulan, dan metode pembelajaran.

Tabel dibawah ini memaparkan tentang tampilan isi video yang dihasilkan melalui proses perancangan konsep produksi media.

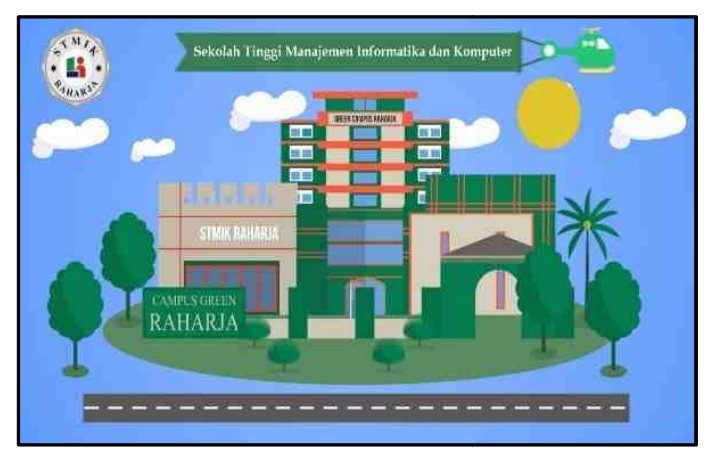

Gambar 12. Scene 1.Bumper Opening Gedung STMIK Raharja

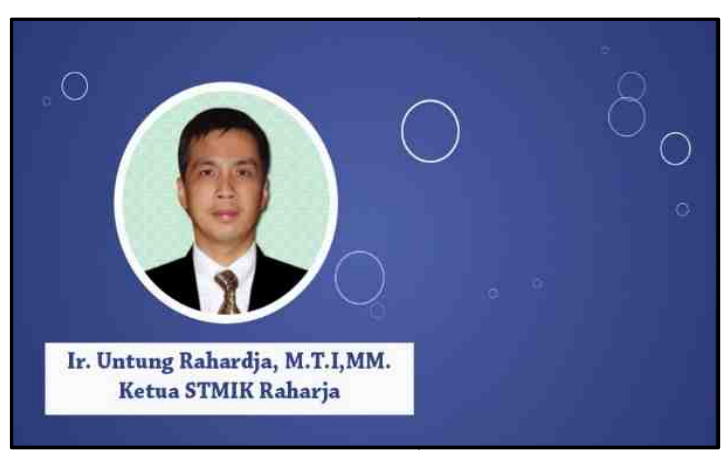

Gambar 13. Scene 2. Menampilkan Ketua STMIK Raharja 


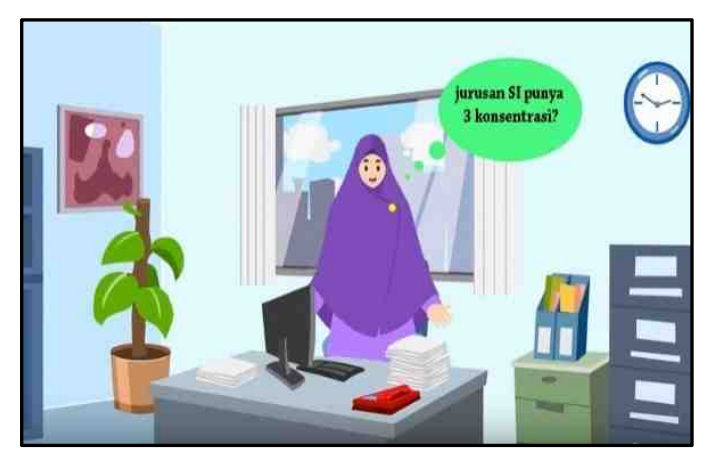

Gambar 14. Scene 3.Mengambarkan penjelasan Kaprodi tentang program studi Sistem Informasi.

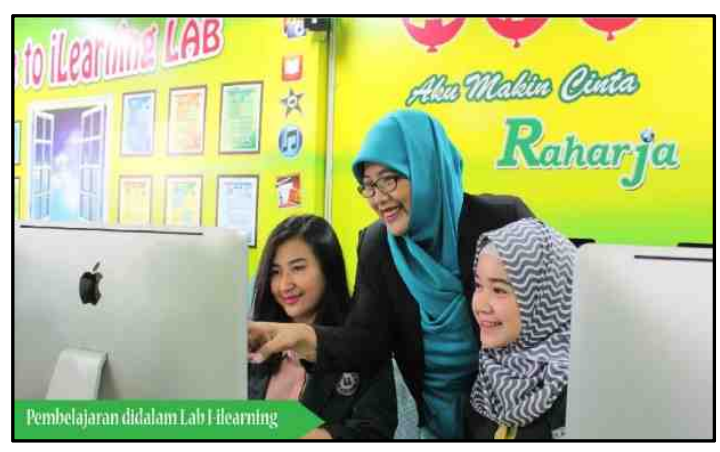

Gambar 16. Scene 5.Menampilkan Fasilitas Jurusan Sistem Informasi.

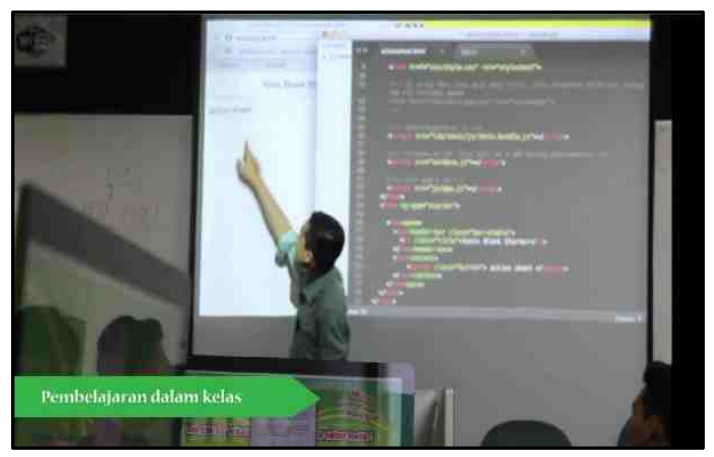

Gambar 18. Scene 7.Menampilkan metode Pembelajaran dalam kelas.

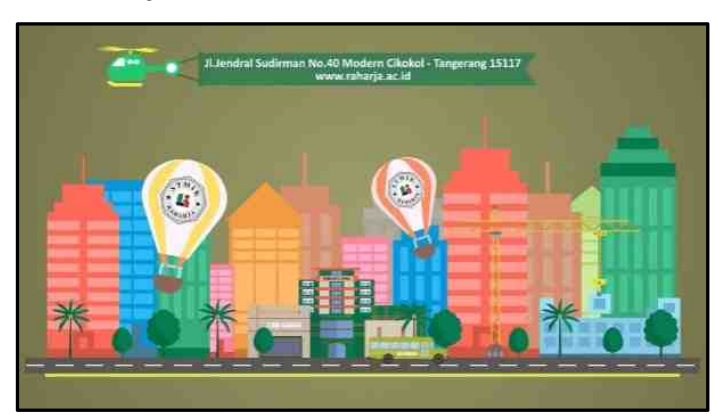

Gambar 20. Scene 9. Bumper Ending

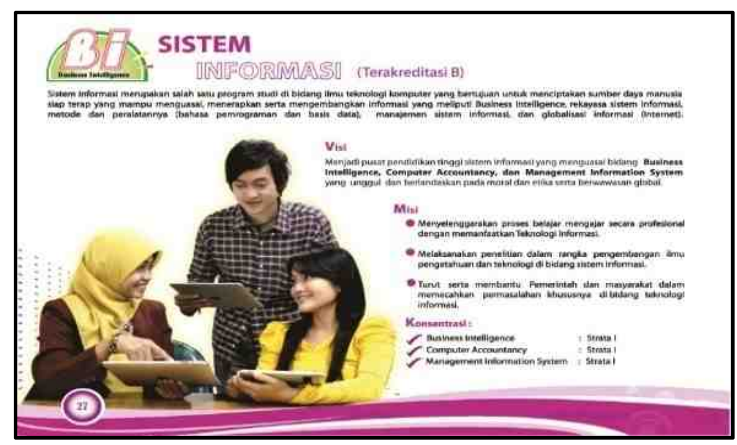

Gambar 15. Scene 4. Profil Jurusan dan Visi Misi Program studi Sistem Informasi.

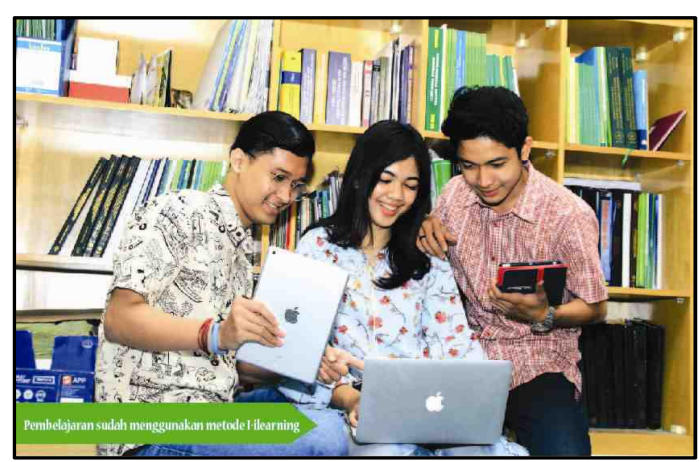

Gambar 17 Scene 6. Menampilkan metode Pembelajaran Jurusan Sistem Informasi

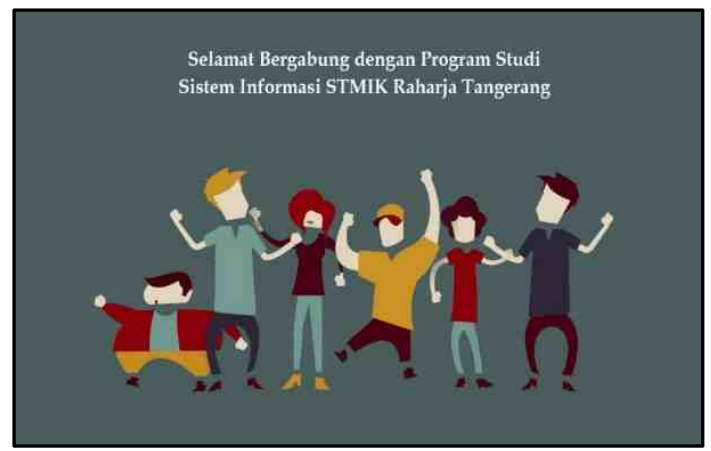

Gambar 19. Scene 8. Menampilkan promosi Jurusan Sistem Informasi STMIK Raharja 


\section{KESIMPULAN}

Media promosi dan informasi yang dibutuhkan jurusan Sistem Informasi pada STMIK Raharja Tangerang adalah Video Promosi berbasis Motion Graphic2D yang mencakup unsur gerak, gambar, suara, dan juga musik yang menjelaskan secara detail mengenai profil jurusan SI STMIK Raharja, konsentasi yang ada di Jurusan SI, fasilitas, keunggulan, dan metode pembelajaran.

Video promosi ini akan ditunjukan kepada calon mahasiswa/i baru yang berminat untuk mengambil jurusan Sistem Informasi dan sebagai media informasi dan promosi bagi masyarakat luas.Perancangan media video promosi jurusan SI STMIK Raharja ini,akan meningkatkan kepeminatan calon mahasiswa/i baru pada jurusan SI STMIK Raharja setiap tahunnya dan menjadi sarana informasi yang bermanfaat bagi masyarakat.Strategi promosi yang dilakukan yaitu : video promosi jurusan SI ini akan di tayangkan pada saat kegiatan GCC Tour, Presentasi internal oleh bagian marketing, Presentasi ke sekolah-sekolah SMA/SMK, education fair, dan berbagai kegiatan promosi lainnya dalam upaya meningkatkan angka pendaftaran mahasiswa/i baru jurusan SI STMIK Raharja setiap tahunnya.

Melalui perancangan media video promosi jurusan SI STMIK Raharja ini diharapkanakan mencapai target pencapaian calon mahasiswa/i baru pada jurusan SI STMIK Raharja setiap tahunnya, dan masyarakat lebih mengenal dan mengetahui informasi mengenai jurusan SI STMIK Raharja Tangerang.

\section{SARAN}

Dengan adanya media informasi berupa audio visual ini disarankan agar media tersebut dipergunakan dan diperbarui agar visi dan misi Program Studi Sistem Informasi Pada STMIK Raharja Tangerang dapat tercapai.

Disarankan kepada Program Studi Sistem Informasi Pada STMIK Raharja untuk melakukan program promosi melalui video promosi berbasis Motion Graphic terus dilakukan, sesuai dengan informasi terupdate mengenai Program Studi Sistem Informasi, serta jadwal yang telah ditentukan dan memperluas pangsa pasar, karena dapat berpengaruh terhadap pengetahuan calon mahasiswa/i baru yang ingin memilih program studi Sistem Informasi Pada STMIK Raharja.

Agar lebih kreatif lagi dalam mempresentasikan profil Program Studi Sistem Informasi Pada STMIK Raharja Tangerang dengan menggunakan video promosi berbasis motion graphic. Karena masyarakat pada umumnya mudah bosan untuk menyimak sebuah informasi yang kurang menarik.Masyarakat dapat melihat melalui media social yang dimiliki sekolah seperti facebook, website, youtube, display dikampus yang ditampilkan kepada orang tua dan calon mahasiswa baru yang mendaftar ataupun masyarakat pada umumnya.

\section{DAFTAR PUSTAKA}

[1] Permana, Yasa Sidik, 2012,Perancangan dan Pembuatan Video Promosi Wisata Ala Dan Edukasi Lingkungan Dolandeso Boro Daerah Banjar Asri Kabupaten Kulon Progo, Yogyakarta, STMIK AMIKOM.

[2] Desrianti, Dewi Immaniar, Sudaryono, dan Dwi Ayu Ningrum, 2014,Enriching Media Merchandise Sarana Penunjang Promosi Studi Kasus pada Bookstore,CCIT Journal Vol.7 No.3,Tangerang, Perguruan Tinggi Raharja.

[3] Wardhani, Rahmi Kesuma dan Iman Sudjudi, 2014,Perancangan Video Dokumenter Autisme, Vol.3 No.1, Bandung, Institut Teknologi Bandung

[4] Win, Nolfian dan Aileena Solicitor Costa Rica El Chidtian, 2015,Video Motion Graphic Sebagai Promosi Perpustakaan Bank Indonesia, Creativitas Vol.4 No.2, Surabaya, Universitas Pembangunan Nasional "Veteran" Jawa Timur. 
[5] Abdillah, Fadhly, Damar Adhiguna,dan Agus Sevtiana, 2017,Perancangan Video Profile Sebagai Media Promosi STMIK CIC Dengan Tehnik Motion Graphic Menggunakan Perangkat Lunak Komputer Graphic, Jurnal DIGIT Vol.7. No.1, Cirebon, STMIK CIC Cirebon.

[6] Anita, Ria Diajeng dan Fitri Marisa, 2017,Rancangan Video Media Promosi Berbasis Motion Graphic 2D Untuk Meningkatkan Jumlah Mahasiswa Universitas Widyagama Malang,Journal of Information Technology and Computer Science (JOINTECS), Vol. 1, No. 2, Malang, Universitas Widyagama.

[7] Yeresella, Destri, Anthony Y.M, Tumimomor, dan Martin Setyawan, 2016,Perancangan Media Video Bahaya Rokok Bagi Ibu Hamil dan Janin BerbasisMotion Graphic, Salatiga, Universitas Kristen Satya Wacana.

[8] Brigitta, Yessica, Eko Sediyono, dan Frederik Samuel Papilaya. 2016. Perancangan Video Company Profile Lembah Kamuning Dairy Farm, Desa Cigugur, Kuningan Daerah Teknik Motion Graphic, Salatiga, Universitas Kristen Satya Wacana. 